\title{
TRAF6 Affects RAC1 Expression and Apoptosis in SK-Hep1 Cells
}

\author{
Shanlei Zhang, Changshi Qian, Xiaochen Liu, Shengjun Piao, Xinglin Jin* \\ Department of Hepatopancreatobiliary Surgery, Affiliated Hospital of Yanbian University, Yanji, China \\ Email: *xljinyj@163.com
}

How to cite this paper: Zhang, S.L., Qian, C.S., Liu, X.C., Piao, S.J. and Jin, X.L. (2018) TRAF6 Affects RAC1 Expression and Apoptosis in SK-Hep1 Cells. Chinese Medicine, 9, 179-189.

https://doi.org/10.4236/cm.2018.94011

Received: November 26, 2018

Accepted: December 24, 2018

Published: December 27, 2018

Copyright $\odot 2018$ by authors and Scientific Research Publishing Inc. This work is licensed under the Creative Commons Attribution International License (CC BY 4.0).

http://creativecommons.org/licenses/by/4.0/

\begin{abstract}
$\mathrm{RAC1}$ is a small-molecule $\mathrm{G}$ protein that regulates multiple cell cycle, cytoskeletal reorganization, cell migration, and apoptosis. FADD-dependent TRAIL can promote tumor metastasis through RAC1 and PI3K, and down-regulating RAC1 expression can reduce FasL-induced apoptosis. In addition, RIP1 bound to GTP acts as an activating protein for $\mathrm{RAC1}$ and is involved in cytoskeletal reorganization. TRAF6 promotes migration and metastasis by regulating the RAS pathway in tumors. Thus, it is necessary to understand the interaction between RAC1 and TRAF6 as well as FADD and RIP1. In this study, we cultured hepatoma SK-Hep1 cells in vitro, specifically blocked the necroptosis pathway with $\mathrm{Nec}-1$, and silenced FADD, RIP1 and TRAF6 gene expression using RNAi technology. At the same time, the expression of RAC1 was evaluated separately using RT-PCR and Western blot. The hepatoma SK-Hep1 cells survival rate was highest when the concentration of Nec-1 was $60 \mu \mathrm{M}$ and the concentration of Z-vad-fmk was $20 \mu \mathrm{M}$. And the apoptosis rate of the transfected RAC1 siRNA cells was $3.59 \%$ compared with transfected siRNA cells $10.01 \%$ which was significantly decreased $(\mathrm{P}<0.01)$. RAC1 could promote the occurrence of apoptosis in SK-Hep1 cells. RAC1 expression was suppressed in both protein and gene level in SK-Hep1 cells when the TRAF6 gene was silenced, but there was no significant change in RAC1 gene and protein expression when FADD and RIP1 genes were silenced. TRAF6 affects RAC1 expression and apoptosis in SK-Hep1 cells, while the FADD and RIP1 genes do not affect the role of RAC1. The TRAF6 gene is an important target in liver cancer cells.
\end{abstract}

\section{Keywords}

Apoptosis, RAC1, TRAF6, FADD, RIP1, SK-Hep1 Cells

\section{Introduction}

Hepatocellular carcinoma (HCC) is the fifth most frequent malignancy in the 
world [1]. With a mortality rate of about one million per year, it ranks as the third leading cause of cancer deaths worldwide [2]. Several main environmental factors are considered to contribute to HCC, such as long-time exposure to aflatoxin B1, hepatitis B and C viral infections, and alcohol abuse [3] [4] [5]. Despite great progress made in HCC diagnosis and therapy, there remain limitations in early detection, and advanced-stage patients, when diagnosed, generally face dismal prognosis and a high incidence of recurrence [6] [7].

Ras-associated C3 botulinum substrate 1 (RAC1) has long been recognized as an important regulatory protein for different physiological and disease processes [8]. Rac1 represents an attractive and innovative target for many types of cancers [9]. Rac1 can mediate the activation of several oncogenic pathways, including

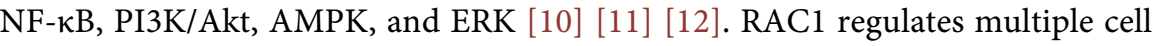
cycle, cytoskeletal reorganization, cell migration, and apoptosis [13]. TRAF6 is involved in a variety of physiological processes, including congenital immunity, adaptive immunity, and inflammation [14]. The current assumed signaling cascade from RANK to ROS production is RANK, TRAF6, Rac1, and then NOX [15]. As for the role of TRAF6 in cancer invasion and metastasis, a study on esophageal squamous cell carcinoma revealed that TRAF6 promoted migration and metastasis by regulating the RAS pathway [16]. RIP1 is a crucial molecule for signaling NF- $\kappa B$, MAPKs, and ROS etc. [17] [18]. It is a kinase with diverse and context-specific roles in inflammation, cell survival, and cell death [17] [19]. RIP1 functions at the crossroads of the cell's decision to live or die upon exposure to several stress signals such as cytokines, pathogen infections, and genotoxic stress. FADD-dependent TRAIL can promote tumor metastasis through RAC1 and PI3K, and down-regulating RAC1 expression can reduce FasL-induced apoptosis [20]. In addition, RIP1 bound to GTP acts as an activating protein for RAC1 and is involved in cytoskeletal reorganization [21].

In this study, we carry out experiments related to SK-Hep1 hepatoma cells in vitro to clarify the effect of RAC1 on apoptosis, and the relationship between RAC1 and TRAF6, as well as FADD and RIP1, in hepatoma cells.

\section{Materials and Methods}

Cell lines and main reagents. The human hepatoma cell line SK-Hep1 was purchased from the cell bank of the Chinese Academy of Sciences. Necrostatin-1 (Nec-1) was purchased from Sigma (USA). FADD siRNA, RIP1 siRNA, and TRAF6 siRNA were purchased from Shanghai Gemma Pharmaceutical Technology Co., Ltd. (China), antibodies were purchased from Elabscience Biotech Co., Ltd., and primers and designs were purchased from Invitrogen Biotech (USA).

Cells culture and treatment. SK-Hep1 cells were cultured in DMEM medium containing $10 \%$ fetal bovine serum (FBS) at $37^{\circ} \mathrm{C}$ and $5 \% \mathrm{CO}_{2}$, and the cells were passaged when cells adhered to the cells to $80 \%$ or more. Cells $\left(3 \times 10^{5}\right)$ were inoculated into a 6-well plate for 24 hours, and after adding Nec-1 and Z-vad-fmk, 
the culture was continued for 24 hours.

MTS assay. DMEM containing 10\% FBS and SK-Hep1 cells were well mixed and inoculated into a 96-well plate $\left(10^{4}\right.$ cells/well $)$ and cultured at $37^{\circ} \mathrm{C}$ in a $5 \%$ $\mathrm{CO}_{2}$ incubator for 24 hours. Different concentrations of Nec-1 $(30 \mu \mathrm{M}, 60 \mu \mathrm{M}$, $90 \mu \mathrm{M}$ ) were added to culture for 24 hours. The cells were treated with MTS cell proliferation kit (solarbio, China) for $3 \mathrm{~h}(20 \mu \mathrm{L} /$ well $)$. The wavelength of 490 $\mathrm{nm}$ was selected to determine the light absorption (OD) value of each well. The cell survival rate was calculated, and the optimal concentration of Nec-1 was screened.

Flow cytometry assay. Analysis was performed using the Annexin V-FITC/PI kit (BD, USA). Cells harvested by Racl siRNA for $48 \mathrm{~h}$ were collected, washed twice with pre-chilled PBS, resuspended by adding $100 \mu \mathrm{L}$ of $1 \times$ Binding Buffer, and the cells were collected, approximately $3 \times 10^{5}$ cells/tube. Add $5 \mu \mathrm{L}$ of Annexin V-FITC and mix well. Allow to stand at room temperature for $15 \mathrm{~min}$ in the dark. Add $5 \mu \mathrm{L}$ PI and $400 \mu \mathrm{L} 1 \times$ Binding Buffer. Apoptosis rate was measured using FACS Calibur (BD, USA).

Gene transfection. Each siRNA $10 \mu \mathrm{l}$ and $10 \mu \mathrm{l}$ LipofectamineTM 2000 (Invitrogen, USA) were added into the blank DMEM medium to mix well. After 20 min, the cells were incubated in $37^{\circ} \mathrm{C}$ incubator for $6 \mathrm{~h}$, then replaced with $10 \%$ FBS in DMEM medium for $48 \mathrm{~h}$. The transfection effect was observed. The siRNAs sequence is as follows:

FADD: 5'-GCCUAGACCUCUUCUCCAUTT-3';

RIP1: 5'-CCUUCUGAGCAGCUUGAUUTT-3';

TRAF6: 5'-GUCGCCUUGUAAGACAAGATT-3';

RAC1:5'-GGACAAGAAGATTATGACA-3';

Negative Control: 5'-UUCUCCGAACGUGUCACGUTT-3'

$R T-P C R$. Total RNA was collected and extracted using Trizol reagent (Life Technologies, USA). After quantification of the samples, cDNA was reversely transcribed using a synthetic kit (Promega, USA) and amplified using a Green Supermix (Promega, USA) in a specific PCR cycle. Finally, the expression of each mRNA was detected in a gel electrophoresis apparatus. The primer sequence is as follows:

GAPDH forward 5'-ACCACAGTCCATGCCATCAC-3', reverse 5'-TCCACCACCCTGTTGCTGTA-3';

FADD forward 5'-GCTCAAGTTCCTATGCCTCG-3', reverse 5'-TGACGTTAAATGCTGCACAC-3';

RIP1 forward 5'-GGCTTTGGGAAGGTGTCTCT-3', reverse 5'-TCATCTTCGCCTCCTCCAAG-3';

TRAF6 forward 5'-AGCTCCTGTAGCGCTGTAAC-3', reverse 5'-CTGGACATTTGTGACCTGCAT-3';

RAC1 forward 5'-ATGCAGGCCATCAAGTGTGTG-3', reverse 5'-CTTCTTGTCCAGCTGTATCCCA-3'.

Western blot. Total protein was extracted using RIPA Lysis Buffer (Solarbio, China) and quantified using BCA Protein Assay Kit (Solarbio, China). SDS-PAGE 
gels of different concentrations were prepared based on the molecular weight of each protein and separated using a $100 \mathrm{~V}$ constant voltage electrophoresis system. Proteins were transferred to PDVF membrane for $1.5 \mathrm{~h}$, and $10 \%$ skimmed milk powder was blocked for $1 \mathrm{~h}$. Primary antibodies (FADD, RIP1, TRAF6, RAC1, 1:1000, and $\beta$-actin, 1:2000) were added and incubated overnight at $4^{\circ} \mathrm{C}$. After washing 3 times with TBST, secondary antibody (1:1000) was added, incubated for $1 \mathrm{~h}$ at room temperature and washed 3 times with TBST. The ECL luminescent color solution (Solarbio, China) was prepared at a ratio of 1:1. The PDVF membrane was soaked for 5 minutes and photographed and analyzed with FluorChem HD2 and FC2 software (Protein Simple, USA).

Statistical analysis. SPSS 17.0 software and GraphPad Prism 7.0 software were used to analyze the data. The measurement results were expressed as mean \pm standard deviation, and the difference was statistically significant by $\mathrm{t}$-test $(\mathrm{P}<0$. 05).

\section{Results}

Optimal concentration of Nec-1 and $z-V A D-F M K$. Hepatoma SK-Hep1 cells were treated with different concentrations of Nec-1 $(30 \mu \mathrm{M}, 60 \mu \mathrm{M}, 90 \mu \mathrm{M})$ and Z-vad-fmk (10 $\mu \mathrm{M}, 20 \mu \mathrm{M}, 40 \mu \mathrm{M})$ for $24 \mathrm{~h}$. OD values were detected and the relative survival rates were calculated. The $\mathrm{OD}$ value and the cell survival rate were highest when the concentration of Nec-1 was $60 \mu \mathrm{M}$ and the concentration of Z-vad-fmk was $20 \mu \mathrm{M}$. Therefore, $60 \mu \mathrm{M}$ of Nec-1 and $20 \mu \mathrm{M}$ of Z-VAD-FMK were selected to interfere with the cells. See Table 1.

Effect of Nec-1 on apoptosis response. Flow cytometry was used to detect the apoptosis rate. The apoptotic rate of the blank control group was $19.21 \%$; the apoptotic rate interfered with Nec-1 $(60 \mu \mathrm{M})$ was $29.37 \%$; the apoptotic rate interfered with Z-VAD-FMK $(20 \mu \mathrm{M})$ was $4.24 \%$; the apoptotic rate interfered with Nec-1 and Z-VAD-FMK was $13.19 \%$. The difference in apoptotic rate was statistically significant $(\mathrm{P}<0.01)$. See Figure 1 .

Effect of RACl on apoptotic rate. The RAC1 siRNA was transfected into SK-Hep1 cells, and the transfection effect was detected through RT-PCR. The results show that RAC1 mRNA expression was significantly reduced $(\mathrm{P}<0.01)$. See Figure 2. Further flow cytometry analysis showed that the apoptotic rate of the untreated cell group (a) was $9.37 \%$, the apoptosis rate of the transfected siRNA group (b) was $10.01 \%$, and the apoptosis rate of the transfected RAC1 siRNA cell group (c) was increased to $3.59 \%$. Compared with group (b), the

Table 1. OD (490 nm) and CSR of SK-Hep1 cells treated with Nec-1 and z-VAD-FMK for $24 \mathrm{~h}$

\begin{tabular}{ccccccccc}
\hline & \multirow{2}{*}{ negative } & DMSO & \multicolumn{3}{c}{ Nec-1 $(\mu \mathrm{M})$} & \multicolumn{3}{c}{ Z-VAD-FMK $(\mu \mathrm{M})$} \\
\cline { 3 - 9 } & & $(2 \mu \mathrm{L} / \mathrm{ml})$ & 30 & 60 & 90 & 10 & 20 & 40 \\
\hline OD & $0.81 \pm 0.02$ & $0.80 \pm 0.01$ & $0.85 \pm 0.02$ & $0.87 \pm 0.03^{*}$ & $0.84 \pm 0.03$ & $0.73 \pm 0.03$ & $0.75 \pm 0.06^{*}$ & $0.71 \pm 0.04$ \\
CSR & $100.00 \%$ & $98.11 \%$ & $104.72 \%$ & $107.27 \%$ & $103.53 \%$ & $91.10 \%$ & $92.58 \%$ & $87.82 \%$ \\
\hline
\end{tabular}

CSR: cell survival rate, ${ }^{*}$ compared with DMSO group, $\mathrm{P}<0.05$. 


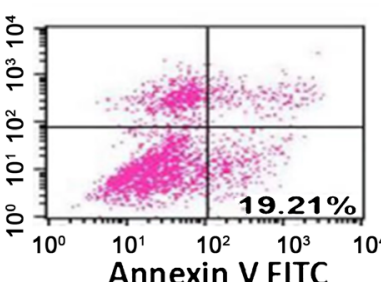

(a)

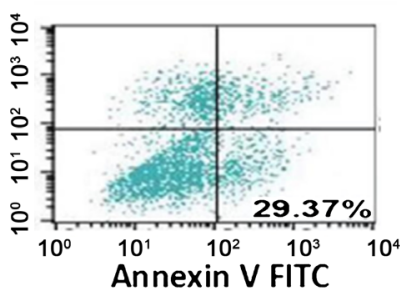

(b)

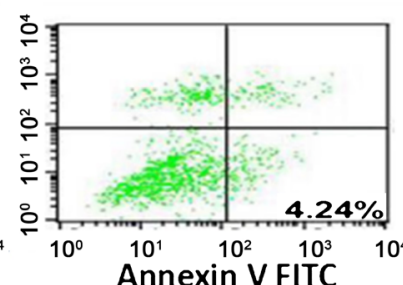

(c)

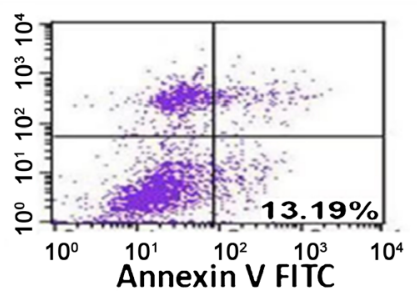

(d)

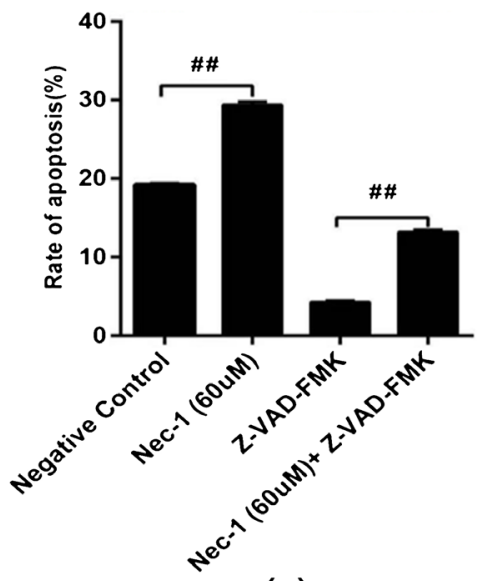

(e)

Figure 1. (a) The apoptotic rate of the blank control group was $19.21 \%$; (b) The apoptotic rate interfered with Nec-1 was $29.37 \%$; (c) The apoptotic rate interfered with Z-VAD-FMK was 4.24\%; (d) The apoptotic rate interfered with Nec-1 and Z-VAD-FMK was 13.19\%; (e) A histogram of apoptosis rates for each group $\left({ }^{\# \#} \mathrm{P}<0.01\right)$.

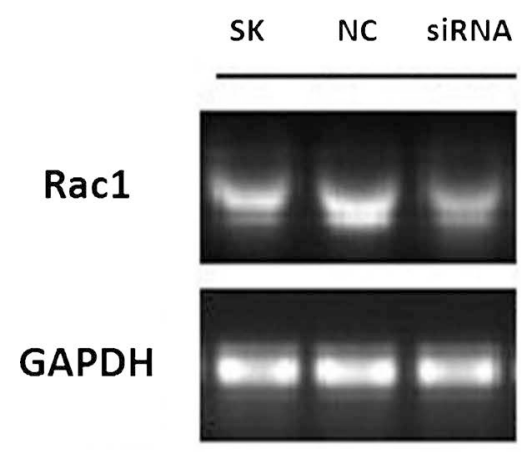

(a)

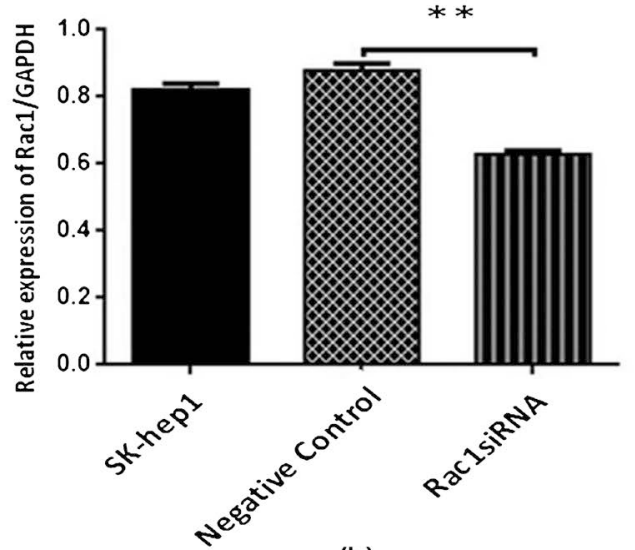

(b)

Figure 2. When RAC1 siRNA was transfected into cells, the expression of RAC1 mRNA decreased significantly $\left({ }^{* * P}<0.01\right)$.

apoptosis rate of group $\mathrm{C}$ was significantly decreased $(\mathrm{P}<0.01)$, demonstrating that when RAC1 expression is inhibited, the number of apoptotic cells is reduced. In other words, RAC1 can promote the occurrence of apoptosis. See Figure 3.

Western Blot assay for protein expression. After transfection of FADD siRNA, RIP1 siRNA and TRAF6 siRNA into SK-Hep1 cells, the expression of the three proteins was significantly attenuated $(P<0.01)$, indicating successful transfection and gene silencing. See Figure 4. When TRAF6 was silenced, RAC1 protein 

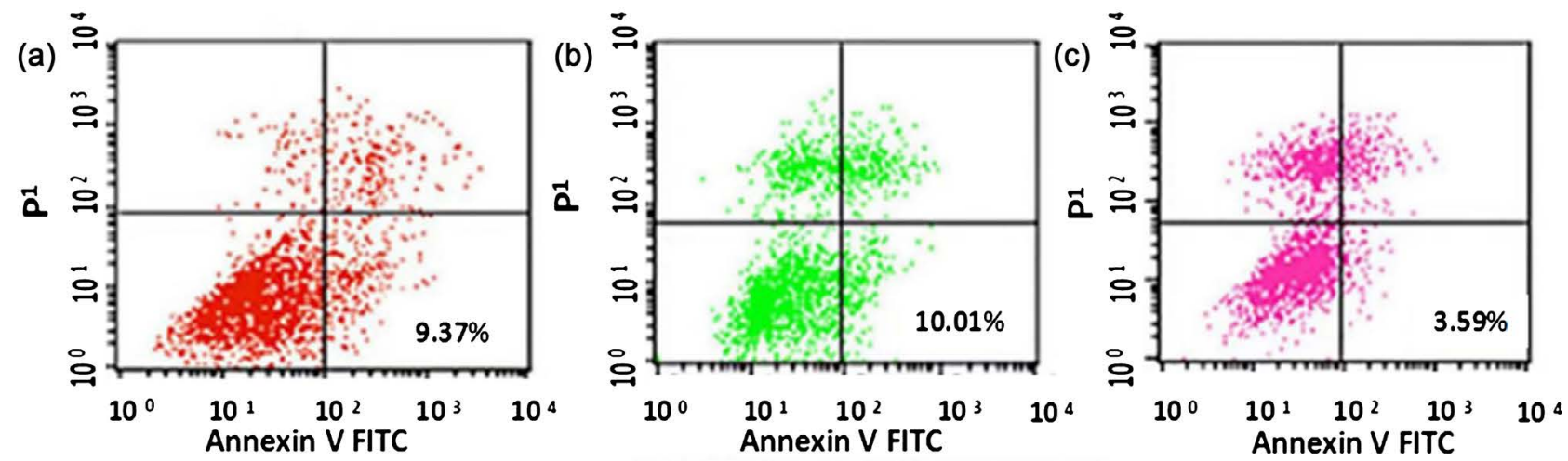

(d)

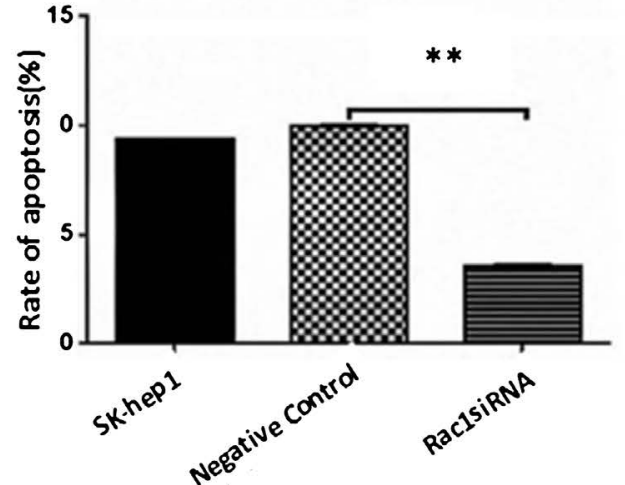

Figure 3. Flow cytometric analysis of apoptosis in SK-Hep1 cells. (a) Untreated cells (9.37\%); (b) Blank control (10.01\%); (c) Group transfected with RAC1 siRNA (3.59\%); (d) Bar graph of apoptosis rate $\left.{ }^{* *} \mathrm{P}<0.01\right)$.

(a) SK-Hep1

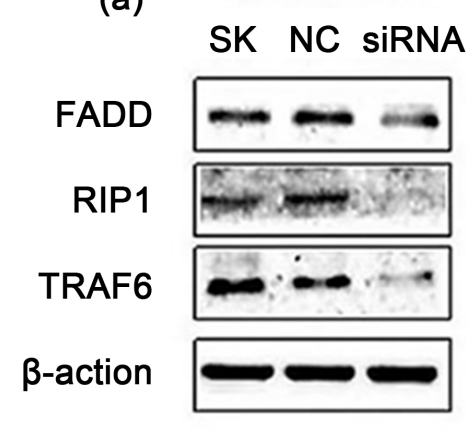

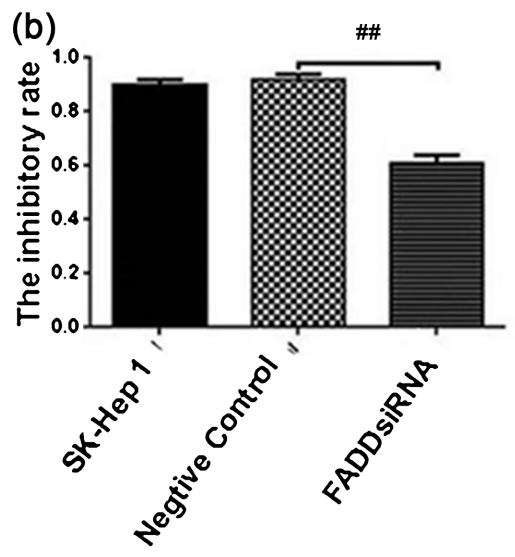
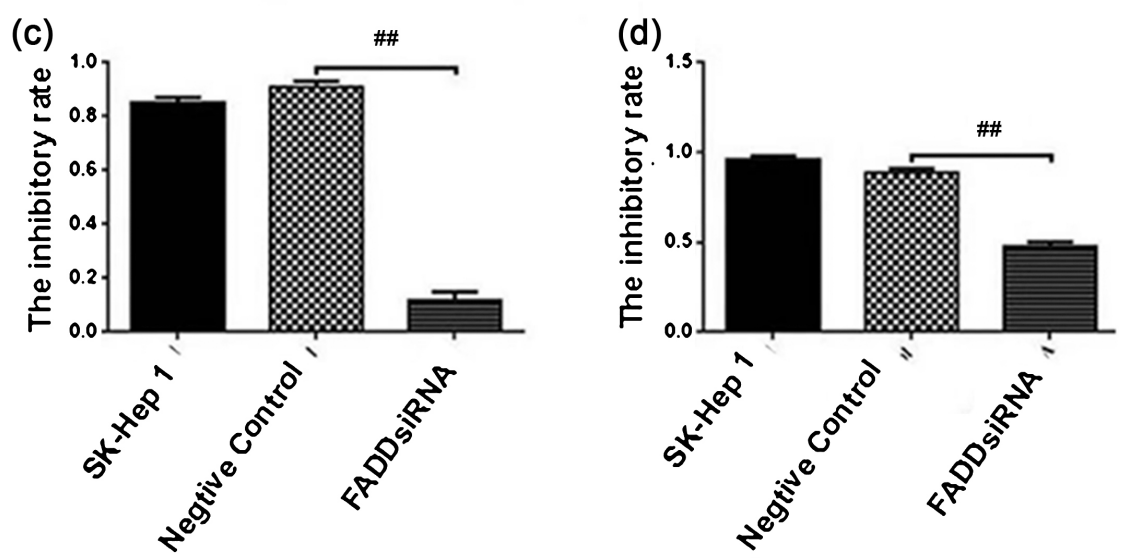

Figure 4. Expression of three proteins after transfection of FADDsiRNA, RIP1siRNA, and TRAF6siRNA by Western blot in SK-Hep1 cells. The protein expression of FADD, RIP1 and TRAF6 decreased significantly after transfection $\left({ }^{\# \#} \mathrm{P}<0.01\right)$. 
expression decreased $(\mathrm{P}<0.01)$; after silencing FADD and RIP1, there was no significant change in RAC1 protein expression $(\mathrm{P}>0.05)$. See Figure 5. Therefore, inhibition of TRAF6 expression can reduce the expression of the Rac1 protein.

$R T-P C R$ detection of RAC1 $m R N A$ expression. Based on the changes in protein expression, the expression of RAC1 mRNA was further examined. The results show that after transfection with TRAF6 siRNA, the expression of RAC1 mRNA was significantly decreased $(\mathrm{P}<0.01)$; after transfection with FADD siRNA and RIP1 siRNA, RAC1 mRNA showed no significant change $(P>0.05)$. See Figure 6. Thus, inhibition of TRAF6 can reduce the expression of Rac1 mRNA.
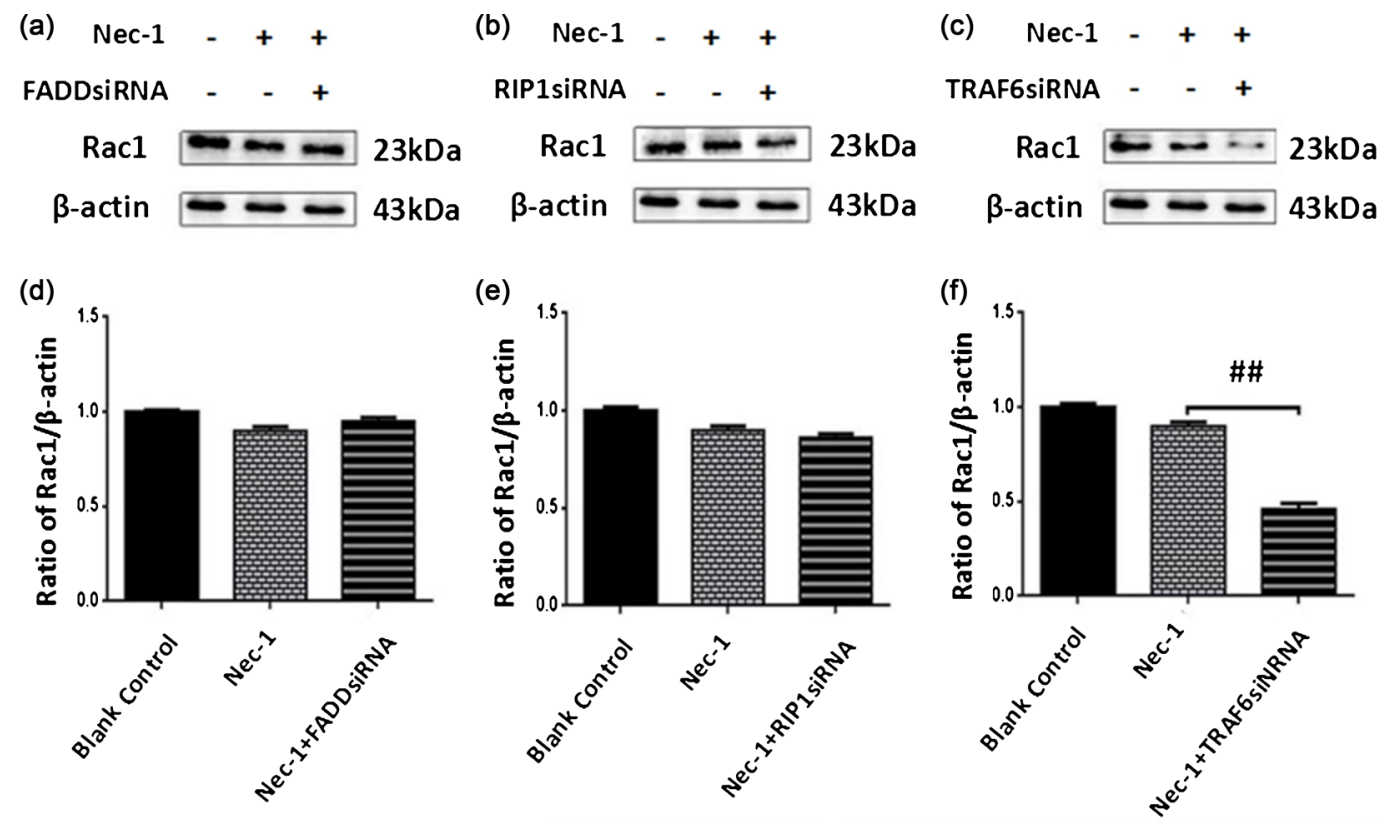

Figure 5. (a)-(c) The expression of the RAC1 protein was decreased after TRAF6 silencing, while the expression of the RAC1 protein had no significant change after FADD and RIP1 silencing; (d)-(f) Ratios of RAC1 protein ${ }^{\# \# P<0.01) . ~}$

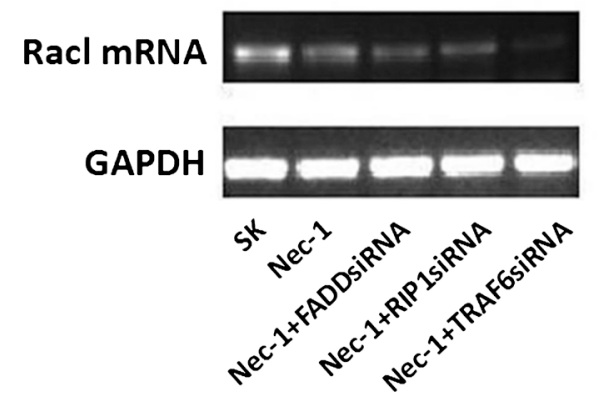

(a)

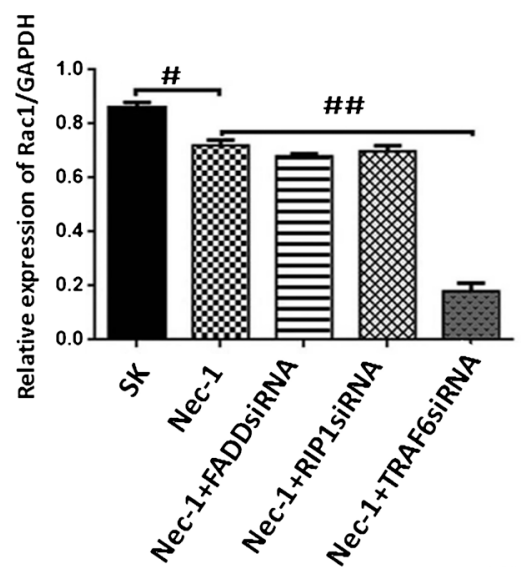

(b)

Figure 6. (a) After the addition of Nec-1, the expression of RAC1 mRNA was attenuated by RT-PCR $(\mathrm{P}<0.05)$; on this basis, FADD, RIP1 and TRAF6 was silenced, the expression of RAC1 mRNA was significantly reduced in the TRAF6siRNA group (P < 0.01 ). While there was no significantly change in the FADDsiRNA, RIP1siRNA group (b) Ratio of RAC1 mRNA in the different group $\left({ }^{\#} \mathrm{P}<0.05,{ }^{\# \#} \mathrm{P}<0.01\right)$. 


\section{Discussion}

The mechanisms that can induce apoptosis in cancer cells are complex and diverse and involve a variety of signaling pathways [22]. RAC1 regulates many different functions, including the involvement of specific effects in the organization of the actin cytoskeleton, cell migration, cell cycle, and cell survival [23]. RAC1 dysregulation can lead to numerous disorders and malignant transformation [24]. The siRNA-mediated knockdown of RAC1 expression in leukemia cell lines has been proved to inhibit cell proliferation, migration and colony formation [25]. In contrast, overexpression of RAC1 increases cell migration and proliferation potential of leukemic cells, which could be implicated in leukemia development and progression [26]. In this study, we focused on the effect of RAC1 on hepatoma SK-Hep1 cell apoptosis. The results showed that RAC1 could promote the occurrence of apoptosis in SK-Hep1 cells. RAC1 is postulated to promote HCC progression by controlling HCC cell apoptosis.

Cells that die by apoptosis, at least in vivo, generally do not release their intracellular contents. However, apoptotic cells do not always die silently because they can trigger the secretion of chemotactic factors and other immunologically active proteins that can influence the immune response toward dying cells [27]. Cells that die by necrosis spill their intracellular contents, and hence trigger an inflammatory response. Nec-1 not only blocks necroptosis, but can also modulate RIP-mediated apoptosis [28]. Nec-1 is therefore not a particularly specific tool to distinguish necroptosis from apoptosis, and conclusions cannot be drawn by using it as a stand-alone approach. Therefore, cell death rescued by Nec-1 can be considered to be necroptosis, and RIP1 is believed to be the key factor in necroptosis. FADD is indispensable for the induction of extrinsic apoptotic cell death. Recent strong evidence from in vivo mice studies has suggested negative roles of FADD in RIP1- and RIP3-dependent necroptosis [29] [30]. FADD deficiency is thought to inhibit caspase-8 and subsequent apoptosis, but activate necroptosis. Upon various stimuli, FADD forms a signaling complex with RIP1 and RIP3, both of which are important to necroptosis induction [31]. TRAF6 also plays an important role in tumorigenesis, invasion and metastasis [32]. Chiu et al. suggested that TRAF6 inhibition might represent a new therapeutic strategy for pancreatic cancer, as the down-regulation of TRAF6 leads to a remarkable increase in autophagy and apoptosis [33]. After TRAF6 was knocked-down with siRNA, cell growth was inhibited in both Hep G2 and Hep3B two cell lines [34]. Peng et al. reported that knock-down of TRAF6 could suppress cell proliferation and promote cell apoptosis in glioma cells [35], and TRAF6 level was increased in colon cancer and its knockdown inhibited cell proliferation, but did not improve survival time [36]. In general, TRAF6 may participate in the cell growth and apoptosis in HCC as well as other cancers. As for the role of TRAF6 in cancer invasion and metastasis, a study on esophageal squamous cell carcinoma revealed that TRAF6 promoted migration and metastasis by regulating the RAS pathway [16]. Therefore, in our study, Nec-1 and 
z-VAD-FMK were interfered, silenced with FADD, RIP1 and TRAF6. When silenced with TRAF6, RAC1 protein expression decreased $(\mathrm{P}<0.01)$; after silencing with FADD and RIP1, there was no significant change in RAC1 protein expression $(\mathrm{P}>0.05)$. Based on the changes in protein expression, the expression of RAC1 mRNA was further examined. The results showed that after transfection with TRAF6 siRNA, the expression of RAC1 mRNA significantly decreased $(\mathrm{P}<0.01)$; after transfection with FADD siRNA and RIP1 siRNA, there was no significant change in RAC1 mRNA $(\mathrm{P}>0.05)$.

\section{Conclusion}

In conclusion, RAC1 could promote the occurrence of apoptosis in SK-Hep1 cells. RAC1 expression was suppressed in both protein and gene level in SK-Hep1 cells when the TRAF6 gene was silenced, but there was no significant change in RAC1 gene and protein expression when FADD and RIP1 genes were silenced. TRAF6 affects RAC1 expression and apoptosis in SK-Hep1 cells, while the FADD and RIP1 genes do not affect the role of RAC1. The TRAF6 gene is an important target in liver cancer cells.

\section{Conflicts of Interest}

The authors declare no conflicts of interest regarding the publication of this paper.

\section{References}

[1] Liu, L., Li, L., Zhou, S., et al. (2014) Familial Correlations of Onset Age of Hepatocellular Carcinoma a Population-Based Case-Control Family Study. PLoS One, 9, e108391. https://doi.org/10.1371/journal.pone.0108391

[2] Wang, R.C., Huang, C.Y., Pan, T.L., et al. (2015) Proteomic Characterization of Annexin 1 (ANX1) and Heat Shock Protein 27 (HSP27) as Biomarkers for Invasive Hepatocellular Carcinoma Cells. PLoS One, 10, e0139232. https://doi.org/10.1371/journal.pone.0139232

[3] Liu, Y., Ren, F., Rong, M., Luo, Y., Dang, Y. and Chen, G. (2015) Association between Underexpression of Microrna-203 and Clinicopathological Significance in Hepatocellular Carcinoma Tissues. Cancer Cell International, 15, 62. https://doi.org/10.1186/s12935-015-0214-0

[4] Hai, H., Tamori, A. and Kawada, N. (2014) Role of Hepatitis B Virus DNA Integration in Human Hepatocarcinogenesis. World Journal of Gastroenterology, 20, 6236-6243. https://doi.org/10.3748/wjg.v20.i20.6236

[5] Papatheodoridis, G.V., Dalekos, G.N., Yurdaydin, C., et al. (2015) Incidence and Predictors of Hepatocellular Carcinoma in Caucasian Chronic Hepatitis B Patients Receiving Entecavir or Tenofovir. Journal of Hepatology, 62, 363-670. https://doi.org/10.1016/j.jhep.2014.08.045

[6] Ma, L., Ji, L., Yu, Y. and Wang, J. (2015) Novel Molecular Targets for Diagnosis and Treatment of Hepatocellular Carcinoma. Discovery Medicine, 19, 7-14.

[7] Fang, P., Hu, J.H., Cheng, Z.G., Liu, Z.F., Wang, J.L. and Jiao, S.C. (2012) Efficacy and Safety of Bevacizumab for the Treatment of Advanced Hepatocellular Carcinoma: A Systematic Review of Phase II Trials. PLoS One, 7, e49717. 
https://doi.org/10.1371/journal.pone.0049717

[8] Wang, J.Y., Yu, P., Chen, S., et al. (2013) Activation of Racl GTPase Promotes Leukemia Cell Chemotherapy Resistance, Quiescence and Niche Interaction. Molecular Oncology, 7, 907-916. https://doi.org/10.1016/j.molonc.2013.05.001

[9] Marei, H. and Malliri, A. (2016) Rac1 in Human Diseases: The Therapeutic Potential of Targeting Rac1 Signaling Regulatory Mechanisms. Small GTPases, 8, 1-25.

[10] Murga, C., Zohar, M., Teramoto, H. and Gutkind, J.S. (2002) Rac1 and RhoG Promote Cell Survival by the Activation of PI3K and Akt, Independently of Their Ability to Stimulate JNK and NF-kappaB. Oncogene, 21, 207-216. https://doi.org/10.1038/sj.onc.1205036

[11] Gastonguay, A., Berg, T., Hauser, A.D., Schuld, N., Lorimer, E. and Williams, C.L. (2012) The Role of Rac1 in the Regulation of NF-kappa B Activity, Cell Proliferation, and Cell Migration in Non-Small Cell Lung Carcinoma. Cancer Biology \& Therapy, 13, 647-56. https://doi.org/10.4161/cbt.20082

[12] Tong, L. and Tergaonkar, V. (2014) Rho Protein GTPases and Their Interactions with NFkB: Crossroads of Inflammation and Matrix Biology. Bioscience Reports, 34, e00115. https://doi.org/10.1042/BSR20140021

[13] Chang, F., Lemmon, C., Lietha, D., Eck, M. and Romer, L. (2011) Tyrosine Phosphorylation of RAC1: A Role in Regulation of Cell Spreading. PLOS ONE, 6, e28587. https://doi.org/10.1371/journal.pone.0028587

[14] Huang, L., Liu, Q., Zhang, L., et al. (2015) Encephalomyocarditis Virus 3C Protease Relieves TANK Inhibitory Effect on TRAF6-Mediated NF-kappa B Signaling through Cleavage of TANK. The Journal of Biological Chemistry, 290, 27618-27632. https://doi.org/10.1074/jbc.M115.660761

[15] Kanzaki, H., Shinohara, F., Kanako, I., et al. (2016) Molecular Regulatory Mechanisms of Osteoclastogenesis through Cytoprotective Enzymes. Redox Biology, 8, 186-191. https://doi.org/10.1016/j.redox.2016.01.006

[16] Han, Q., Yao, F., Zhong, C. and Zhao, H. (2014) TRAF6 Promoted the Metastasis of Esophageal Squamous Cell Carcinoma. Tumour Biology, 35, 715-721. https://doi.org/10.1007/s13277-013-1098-Z

[17] Festjens, N., Vanden Berghe, T., Cornelis, S. and Vandenabeele, P. (2007) RIP1, a Kinase on the Crossroads of a Cell's Decision to Live or Die. Cell Death \& Differentiation, 14, 400-410. https://doi.org/10.1038/sj.cdd.4402085

[18] Vandenabeele, P., Declercq, W., van Herreweghe, F. and Vanden Berghe, T. (2010) The Role of the Kinases RIP1 and RIP3 in TNF-Induced Necrosis. Science Signaling, 3, re4. https://doi.org/10.1126/scisignal.3115re4

[19] Galluzzi, L., Aaronson, S.A., Abrams, J., et al. (2009) Guidelines for the Use and Interpretation of Assays for Monitoring Cell Death in Higher Eukaryotes. Cell Death \& Differentiation, 16, 1093-1107. https://doi.org/10.1038/cdd.2009.44

[20] Hartwig, T., Montinaro, A., von Karstedt, S., et al. (2017) The Trail-Induced Cancer Secretome Promotes a Tumor-Supportive Immune Microenvironment via CCR2. Molecular Cell, 65, 730-742. https://doi.org/10.1016/j.molcel.2017.01.021

[21] Jilkina, O. and Bhullar, R.P. (2006) A Serine Kinase Associates with the RAL GTPase and Phosphorylates RAL-Interacting Protein 1. Biochimica et Biophysica Acta, 1763, 948-957. https://doi.org/10.1016/j.bbamcr.2006.07.007

[22] Li, N., Jiang, J., Fu, J., et al. (2016) Targeting Interleukin-1 Receptor-Associated Kinase 1 for Human Hepatocellular Carcinoma. Journal of Experimental \& Clinical Cancer Research, 35, 140. https://doi.org/10.1186/s13046-016-0413-0 
[23] Nie, F., Zhao, S.Y., Song, F.X. and Li, P.W. (2014) Changes of Cytoskeleton and Cell Cycle in Lovo Cells via Deletion of RAC1. Cancer Biomarkers, 14, 335-342. https://doi.org/10.3233/CBM-140408

[24] Han, J., Weisbrod, R.M., Shao, D., et al. (2016) The Redox Mechanism for Vascular Barrier Dysfunction Associated with Metabolic Disorders: Glutathionylation of RAC1 in Endothelial Cells. Redox Biology, 9, 306-319. https://doi.org/10.1016/j.redox.2016.09.003

[25] Wang, J., Rao, Q., Wang, M., et al. (2009) Overexpression of RAC1 in Leukemia Patients and Its Role in Leukemia Cell Migration and Growth. Biochemical and Biophysical Research Communications, 386, 769-774. https://doi.org/10.1016/j.bbrc.2009.06.125

[26] Mizukawa, B., Wei, J., Shrestha, M., et al. (2011) Inhibition of Rac GTPase Signaling and Downstream Prosurvival Bcl-2 Proteins as Combination Targeted Therapy in MLL-AF9 Leukemia. Blood, 118, 5235-5245.

https://doi.org/10.1182/blood-2011-04-351817

[27] Cullen, S.P., Henry, C.M., Kearney, C.J., et al. (2013) Fas/CD95-Induced Chemokines Can Serve as "Find-Me" Signals for Apoptotic Cells. Molecular Cell, 49, 1034-1038. https://doi.org/10.1016/j.molcel.2013.01.025

[28] Tenev, T., Bianchi, K., Darding, M., et al. (2011) The Ripoptosome, a Signaling Platform That Assembles in Response to Genotoxic Stress and Loss of IAPs. Molecular Cell, 43, 432-448. https://doi.org/10.1016/j.molcel.2011.06.006

[29] Bonnet, M.C., Preukschat, D., Welz, P.S., et al. (2011) The Adaptor Protein Fadd Protects Epidermal Keratinocytes from Necroptosis in Vivo and Prevents Skin Inflammation. Immunity, 35, 572-582. https://doi.org/10.1016/j.immuni.2011.08.014

[30] Lu, J.V., Weist, B.M., van Raam, B.J., et al. (2011) Complementary Roles of Fas-Associated Death Domain (FADD) and Receptor Interacting Protein Kinase-3 (RIPK3) in T-Cell Homeostasis and Antiviral Immunity. Proceedings of the National Academy of Sciences of the United States, 108, 15312-15317. https://doi.org/10.1073/pnas.1102779108

[31] Lee, E., Seo, J., Jeong, M., Lee, S. and Song, J. (2012) The Roles of FADD in Extrinsic Apoptosis and Necroptosis. BMB Reports, 45, 496-508. https://doi.org/10.5483/BMBRep.2012.45.9.186

[32] Meng, Q., Zheng, M., Liu, H., et al. (2012) TRAF6 Regulates Proliferation, Apoptosis, and Invasion of Osteosarcoma Cell. Molecular and Cellular Biochemistry, 371, 177-186. https://doi.org/10.1007/s11010-012-1434-4

[33] Chiu, H.W., Lin, S.W., Lin, L.C., et al. (2015) Synergistic Antitumor Effects of Radiation and Proteasome Inhibitor Treatment in Pancreatic Cancer through the Induction of Autophagy and the Down-Regulation of TRAF6. Cancer Letters, 365, 229-239. https://doi.org/10.1016/j.canlet.2015.05.025

[34] Li, J.J., Luo, J., Lu, J.N., et al. (2016) Relationship between TRAF6 and Deterioration of HCC: An Immunohistochemical and in Vitro Study. Cancer Cell International, 16, 76. https://doi.org/10.1186/s12935-016-0352-Z

[35] Zhang, P., Yue, S., Jiang, Y., Zhang, X. and Liu, Y. (2013) TNF Receptor-Associated Factor 6 Regulates Proliferation, Apoptosis, and Invasion of Glioma Cells. Molecular and Cellular Biochemistry, 377, 87-96. https://doi.org/10.1007/s11010-013-1573-2

[36] Sun, H., Li, X., Fan, L., Wu, G., Li, M. and Fang, J. (2014) TRAF6 Is Upregulated in Colon Cancer and Promotes Proliferation of Colon Cancer Cells. The International Journal of Biochemistry \& Cell Biology, 53, 195-201. https://doi.org/10.1016/j.biocel.2014.04.010 